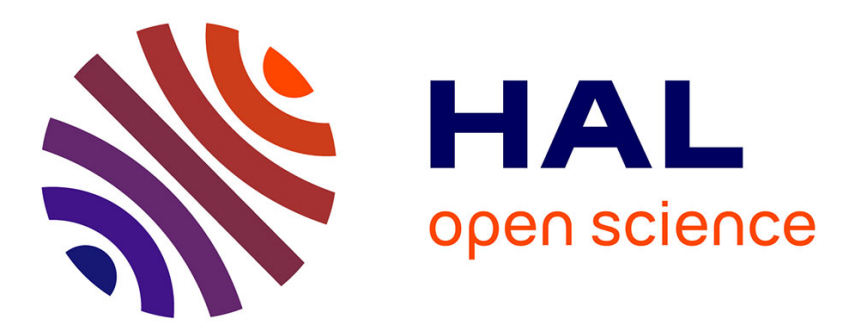

\title{
Evaluation of tribothermal effectiveness of TiAlN-based bilayer coatings in cutting fiber-reinforced polymers
}

\author{
Ali Mkaddem, Bessam Zeramdini, Mohamed El Mansori, Salah Mezlini
}

\section{To cite this version:}

Ali Mkaddem, Bessam Zeramdini, Mohamed El Mansori, Salah Mezlini. Evaluation of tribothermal effectiveness of TiAlN-based bilayer coatings in cutting fiber-reinforced polymers. Tribology International, 2016, 103, pp.176-186. 10.1016/j.triboint.2016.07.003 . hal-02417486

\section{HAL Id: hal-02417486 \\ https://hal.science/hal-02417486}

Submitted on 18 Dec 2019

HAL is a multi-disciplinary open access archive for the deposit and dissemination of scientific research documents, whether they are published or not. The documents may come from teaching and research institutions in France or abroad, or from public or private research centers.
L'archive ouverte pluridisciplinaire HAL, est destinée au dépôt et à la diffusion de documents scientifiques de niveau recherche, publiés ou non, émanant des établissements d'enseignement et de recherche français ou étrangers, des laboratoires publics ou privés. 


\title{
Evaluation of tribothermal effectiveness of TiAlN-based bilayer coatings in cutting fiber-reinforced polymers
}

\author{
Ali Mkaddem ${ }^{\mathrm{a}, \mathrm{b}, *}$, Bessam Zeramdini ${ }^{\mathrm{a}}$, Mohamed El Mansori ${ }^{\mathrm{a}}$, Salah Mezlini ${ }^{\mathrm{c}}$ \\ ${ }^{a}$ MSMP-EA7350, Arts et Métiers ParisTech, Rue Saint Dominique, BP. 508, 51006 Châlons-en-Champagne, France \\ ${ }^{\mathrm{b}}$ Engineering College, Faculty of Engineering, University of Jeddah, PO Box 80327, 21589 Jeddah, Saudi Arabia \\ c Laboratoire Génie Mécanique, École Nationale d'Ingénieurs de Monastir, Université de Monastir, Tunisia
}

Keywords:

TiAlN

Abrasion

Friction

Thermal conductivity

\begin{abstract}
A B S T R A C T
This work addresses the tribological reliability of TiAlN-based PVD coatings face to TiN-based CVD coating in cutting FRP. Wear and linear pin-on-plate tests were conducted on both glass/epoxy and carbon/epoxy composites for investigating wear progression and apparent friction, respectively. The TiAlN location shows great role in controlling wear upon PVD coatings. While abrasion was found dominating the wear mechanisms upon the flank face irrespective to coating type, PVD coatings demonstrate better ability to dissipate severe cratering. Although the all coatings showed close behavior against carbon/epoxy, TiAIN/AlCrO coating revealed great vulnerability against glass/epoxy resulting in extended AlCrO layer failure. While wear substantially reduces the thermal conductivity, PVD coatings kept roughly better conductivities than CVD coating as for worn states.
\end{abstract}

\section{Introduction}

PVD coating techniques proved their efficiency in enhancing tool life in several applications [1]. While advances have been well marked for metals, processing of heterogeneous materials such as composites still involves very challenging task. Although superior specific properties of fiber-reinforced polymers (FRP) are promoting for several applications, their machinability still presents many issues. The fiber abrasiveness is assumed to be the main role in controlling tool behavior. During cutting, the tool undergoes a series of low-to-high cyclic loads due to the properties of fiber and matrix phases. Thermo-mechanical disequilibrium takes place yielding, hence, poor surface finish, local delamination and fibermatrix decohesion. The interface consumption mechanisms resulting in material removal bodies (coating components, fiber particles, matrix debris, etc.) should locally influence the contact properties [2]. The evolution of thermo-mechanical properties at the tool-material interface affects the tool behavior, particularly, the coating endurance. TiAlN coatings consist of effective solution since they exhibit unique properties at elevated temperatures.

Abbreviations: AFM, Atomic force microscope; CFRP, Carbon fiber reinforced polymers; CVD, Chemical vapor deposition; FRP, Fiber reinforced polymers; GFRP Glass fiber reinforced polymers; PVD, Physical vapor deposition; Ti, Titanium; TiN, Titanium nitride; TiAlN, Titanium and aluminum nitride

* Corresponding author at: MSMP-EA7350, Arts et Métiers ParisTech, Rue Saint Dominique, BP. 508, 51006 Châlons-en-Champagne, France.

E-mail addresses: ali.mkaddem@ensam.fr, amkaddem@uj.edu.sa (A. Mkaddem).
Especially, they preserve relatively high hardness with good thermal and chemical stability at high temperature [3-6].

Nowadays, thin hard PVD coatings are available for improving tool ability i.e. reducing friction and wear, in various manufacturing sets. Physical vapor deposition of TiN had marked the earlier development in thin coating technologies [7,8]. TiAlN coatings are among the intensely commercial techniques used for the enhancement of tool life. They can be applied as monolayer or as multilayers in combination with other coating types such as Ti and TiN $[9,10]$. They present a novel set of physical vapor depositions with improved properties (heat resistance, oxidation resistance, hardness, toughness, etc.) if compared with TiN coatings. In spite of the advances achieved, the efficiency of PVD coatings in machining fiber-reinforced composites still remains challenging.

Machining of FRP involves the coated tool to be in aggressive contact with the abrasive surface of the composite component. Thus, the coating resistance depends on the coating properties (coating structure and composition, substrate-to-coating adherence, etc.). The PVD processes feature to enhance both physical and chemical properties of the overall coating [11,12]. TiN/TiAlN is expected to be a promising candidate as a hard coating layer because of excellent properties especially for high temperature applications.

PalDey et al. $[13,14]$ reported that TiAIN coatings by PVD process enhance wear, thermal, and oxidation resistance of large tool variety. In addition to these properties, relatively low thermal conductivity makes these coatings most desirable in dry, abrasive, and high speed machining. Combination of TiAlN with multicomponent 
coatings of complementary properties should lead, in turn, to a further refinement of coating structure. The presence of multiple interfaces between individual coating layers promotes an increase of hardness and strength of multilayered coatings. Li et al. [15] investigated multilayer coating structure composed of different TiAlN/ CrAlN bilayer periods for wear protection. Multilayer structure results typically in an increase in hardness and adhesive strength. Combination of thermal stability of TiAlN and resistance-to-oxidation of CrAlN ensures an improved behavior in machining, irrespective to operating conditions. Mkaddem et al. [16] examined also the performance of multilayer coating structure in cutting composites. From observations, the TiAlN layer of TiN/TiAlN coating shows inefficiency to resist the cratering because of fibers spring-back. However, the same layer made of finer grains upon TiAlN/AlCrO, exhibits better ability in dissipating severe abrasion to the detriment of a faster wear due to better adhesion at layers' interface. Promotion of TiAlN-based multilayered coatings was widely addressed in open literature $[17,18]$.

Currently, TiAlN coatings are assumed to be the second series in commercial hard following TiN coatings [7,19]. Ding et al. [19] measured the thermal conductivity of a series of TiAlN coatings with different $\mathrm{Al} / \mathrm{Ti}$ atomic ratio deposited on AISI304 stainless steel substrate. They outlined a significant decrease in thermal conductivity with increasing $\mathrm{Al} / \mathrm{Ti}$ atomic ratio. A minimum thermal conductivity of about $4.63 \mathrm{~W} / \mathrm{mK}$ was obtained at the $\mathrm{Al} / \mathrm{Ti}$ atomic ratio of around 0.72 . Srinivasan et al. [20] also studied the variation of thermal properties of TiAlN thin films on silicon substrate versus di-nitrogen $\left(\mathrm{N}_{2}\right)$ flow rate. They stated an increase in thermal conductivity with increasing $\mathrm{N}_{2}$ flow rate. The measured values were found significantly lower than those obtained with the TiAlN bulk materials.

Alternating contact between the tool-tip and composite phases consists of actual difficulty in machining. The new coating sets based on multilayer systems meet all the success in machining advanced composites $[2,16,21]$. Wear mechanisms on TiAlN/TiN coated tool have been particularly addressed by Isbilir et al. [22] when drilling carbon fiber-reinforced plastics. While abrasive wear operates on both relief and flank tool faces, no sign of degradation by chipping or plastic deformation were detected upon the drill surfaces. As both carbon and glass fibers significantly enhance the composite strength, the tool resistance is sensitively affected as a consequence [23].

In this paper, the behavior of two TiAlN-based coatings while cutting glass- and carbon fiber-reinforced polymers was investigated. Flank wear progression, friction and thermal conductivity were measured and discussed relatively to the performance of an available commercial CVD multilayered coating.

\section{Experimental procedures}

\subsection{Composite specimens}

The composite panels were firstly prepared at room temperature in $400 \times 400 \mathrm{~mm}$ mold using hand lay-up technique. The cure cycle $[24,25]$ for each used composite was adjusted so as to ensure the best technical solution avoiding deflection of the panels during cooling stage (Fig. 1a). Then, the panels were introduced in a press molding machine to undergo the required cure cycle (Fig. 1b).

The prepregs were supplied by COMPOSITES DISTRIBUTION GROUP (France). Table 1 summarizes the specifications of each phase of both CFRP and GFRP studied materials. After cooling, the panels were pre-trimmed using a diamond wheel to obtain the testing specimen of $100 \times 50 \times 4 \mathrm{~mm}$ in dimensions. Clockwise sense was considered to specify the fiber orientation with respect of tool trajectory. Both wear and friction tests use the same specimen type.

\subsection{Wear tests}

A shaper machine (Model GSP-EL 136) of $5222 \mathrm{~W}$ maximum power, $650 \mathrm{~mm}$ maximum stroke, and $100 \mathrm{~m} \mathrm{~min}^{-1}$ maximum speed was used for conducting wear tests. The capability of two PVD TiAlN-based coatings was investigated and compared to a referred CVD coating. All inserts, supplied by Sandvik Coromant Group, have unique cutting geometry with rake and clearance angles of $0^{\circ}$ and $7^{\circ}$, respectively. The insert is lock-pinned on a tool-holder of model STFCR 2525M 16-4 (ISO). Table 2 summarizes the specifications of the three selected coatings. Wear tests were however limited to the specimen of $45^{\circ}$ fiber orientation since cutting mechanisms in that configuration combines the most wear modes encountered. That configuration is also assumed representative of the most severe conditions at tool-material interface. The feed $(f)$, depth of cut $\left(a_{p}\right)$, and cutting speed $\left(V_{c}\right)$ were fixed to $0.3 \mathrm{~mm}, 4 \mathrm{~mm}$, and $50 \mathrm{~m} \mathrm{~min}^{-1}$, respectively. Dry cutting was ensured through consecutive edge trimming of the top side of

(a)
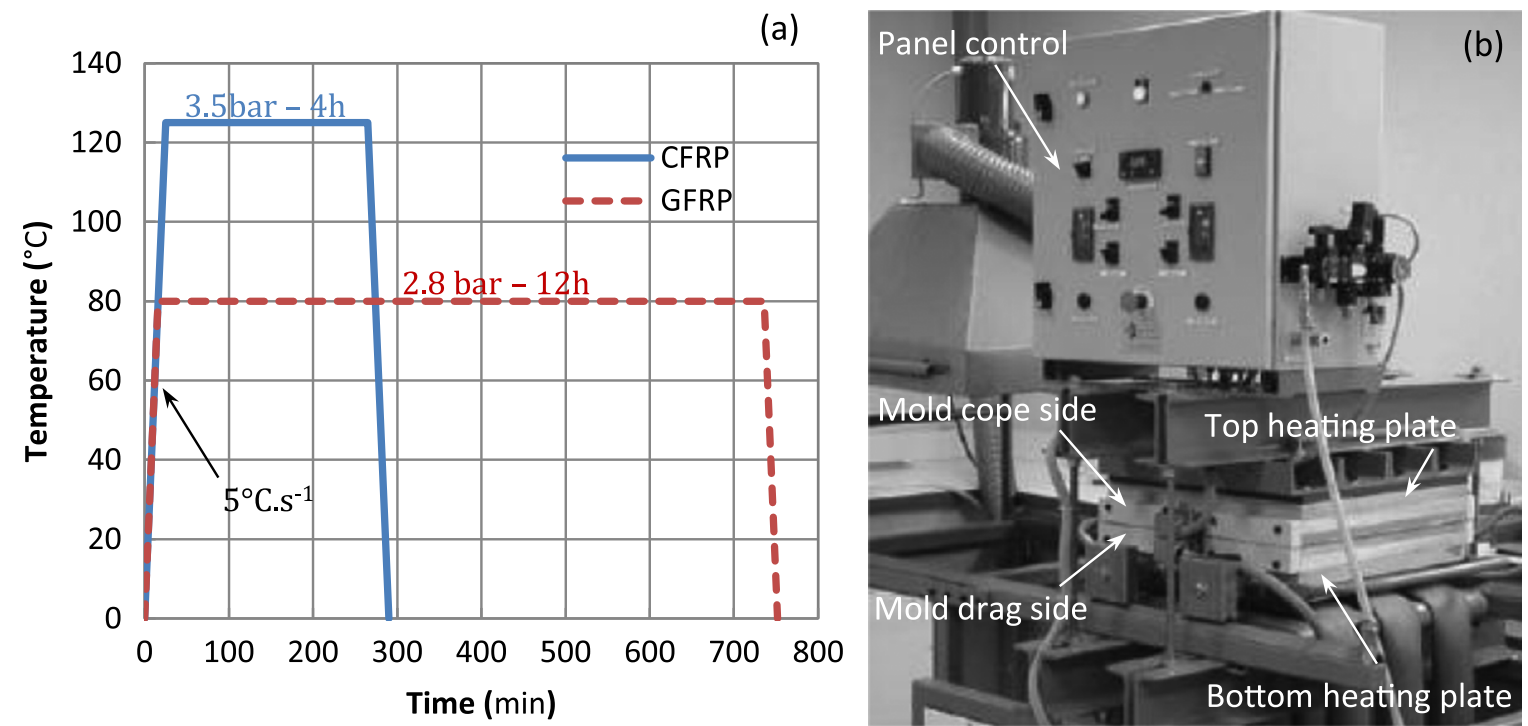

Fig. 1. (a) Press-molding machine, and (b) typical cure cycles used for the fabrication of the considered composites. 
Table 1

Specifications of material constituents used in specimen preparation.

\begin{tabular}{llll}
\hline \multirow{2}{*}{ Propriety } & GFRP & CFRP \\
\hline \multirow{2}{*}{ Prepreg } & Mass nominal & $1418 \mathrm{~g} \mathrm{~m}^{-2}$ & $923 \mathrm{~m}^{-2}$ \\
& Pressure & $0.3-3 \mathrm{bar}$ & $0.3-5 \mathrm{bar}$ \\
\multirow{5}{*}{ Matrix } & Ply thickness & $0.742 \mathrm{~mm}$ & $0.6 \mathrm{~mm}$ \\
& Type & Epoxy BE M10 & Epoxy M9.6G \\
& Glass transition temperature $(\mathrm{Tg})$ & $120^{\circ} \mathrm{C}$ & $120^{\circ} \mathrm{C}$ \\
& Density & $1.2 \mathrm{~g} \mathrm{~cm}^{-3}$ & $1.2 \mathrm{~cm}^{-3}$ \\
\multirow{3}{*}{ Fiber } & Volume fraction & $29.5 \%$ & $35 \%$ \\
& Type & Glass E 2400 & Carbon Panex 35 \\
& Density & $2.6 \mathrm{~g} \mathrm{~cm}^{-3}$ & $1.81 \mathrm{~g} \mathrm{~cm}^{-3}$ \\
& Nominal mass & $1000 \mathrm{~g} \mathrm{~m}^{-2}$ & $600 \mathrm{~g} \mathrm{~m}^{-2}$ \\
\hline
\end{tabular}

the specimen up to a maximum cutting length $\left(l_{c}\right)$ of $100 \mathrm{~m}$, at which dominating wear process becomes substantially invariable. The feed is coordinately adjusted to the target value at each trimming sequence of $0.12 \mathrm{~s}$. A new insert is used to perform the test series of each considered composites. The optical microscope is employed to examine the worn tool surface at different stage of cutting period.

\subsection{Friction tests}

In this work, friction tests were performed in order to assess the apparent friction coefficient. The friction test inserts were chosen to be cutting edge-free to prevent material removal while the coating type was kept the same. Because of cost and time consuming, the design of experiments was restricted to CVD coating and only one PVD coating (Table 3 ). The coated pins are cylindrical of $19.1 \mathrm{~mm}$ in diameter and $6 \mathrm{~mm}$ in effective width. They are lock- pinned so as to prevent any free rotation of the pin during sliding against the composite plate.

Sliding contact between the cylindrical insert and the top side of the specimen results from the relative motion between the fixed table and the shaper ram. Before each test, the top side of the specimen was pre-trimmed to ensure the tool-plate interface to be rectilinear. This ensures a continuous and constant contact pressure during testing step. The fiber orientation $(\theta)$ and applied contact pressure $(P)$ are variables. The former was adjusted by means of Kistler piezoelectric dynamometer (model 9255B) connected to an acquisition device. The sliding speed $\left(V_{S}\right)$ and contact width $\left(w_{c}\right)$ were adjusted to cutting speed and cutting feed used in wear tests, respectively (Table 4). The tool-holder and pin-on-plate system are illustrated in Fig. 2.

\section{Results and discussion}

\subsection{GFRP cutting induced wear}

The microscopic inspections performed on worn faces revealed that flank wear commonly dominates upon the studied inserts (Fig. 3). However, worn area and wear patterns observed on CVD coatings were found neatly different from those observed on PVD coatings. The wear mechanisms induced substantially due to abrasive fibers, acts differently upon the coating layers because of various coating properties. The rapid onset of irregular streaks on the CVD coating reflects a hard abrasion that takes firstly place on TiCN layer before reaching the cemented carbide substrate. While the former coating exhibit discontinuous and randomly oriented wear patterns (Fig. 3a-d), TiAlN-AlCrO PVD coating shows continuous streaks oriented parallel to the tool trajectory. This implicitly refers to the abrasion mode operating on that PVD coating. At early cutting stage $\left(l_{c} \leq 50 \mathrm{~m}\right)$, the material removal still remains localized throughout the outer coating layer made of $\mathrm{AlCrO}$ (Fig. 3e-f). Once that layer was fully removed $\left(l_{c} \geq 50 \mathrm{~m}\right)$, the sharp edges of cut fibers come into contact with the intermediate layer made of TiAlN, which forces wear to progress toward the substrate (Fig. $3 g$ and $h$ ). The micrographs make it possible to distinguish the substrate from the two coating constituents. After $1 \mathrm{~min}$ working period, the coating set completely fails and the damage reaches the substrate. Besides, when abrasion develops close to the tool-tip, erosion mechanisms extends along the frontiers of the AlCrO layer (see Fig. $3 g$ and $h$ ). The observations show fine cratering throughout the worn area, which attributed to the adhesion level between the two coating layers. It can be outlined that PVD technique allows, mostly, better adhesion of coating phases to the substrate, and to each other than CVD one. Following the specifications of the supplier, TiAlN-AlCrO and TiN-TiAlN PVD coatings are classified as with 'medium' and 'high' adhesion, respectively. It appears that adhesion of TiAlN-AlCrO to the substrate is not high enough to efficiently resist the action of abrasive glass fibers. However, adhesion between the two coating layers seems to be so enough so that to reduce wear to a local cratering mechanisms acting in TiAlN intermediate layer. The relatively good adhesion at TiAlN/AlCrO interfaces is essentially attributed to the ultra-fine grains constituting the coating layers as mentioned in the coating specifications. This grain grade is crucial for reaching a thickness of $2 \mu \mathrm{m}$ in such a coating. The coating thickness has tendency to increase with the grain number. An increase in grain number through the thickness multiplies the interfaces at grain boundaries which relatively alters adhesion quality and favors, in turn, premature degradation of the coating. Nevertheless, the deep streaks observed on the CVD worn land result practically in the relatively coarse grains forming the coating layers. As obvious, the failure of grain boundaries is neatly more probable than breaking-up a grain itself. Unexpectedly, the TiAlN-AlCrO coated insert exhibited good ability to produce neat GFRP surfaces in spite of its high vulnerability to degradation. From observations, it was revealed that the former has the sharpest cutting edge as compared to the other considered inserts.

Even if abrasion mode acts also upon the TiN-TiAlN coating, it exhibits slower progression than the other used coatings. The good adhesion property of TiN [16] plays a great role in resisting

Table 2

Design of experiments for wear analysis, and thermal conductivity measurements.

\begin{tabular}{|c|c|c|c|c|c|}
\hline Nuances used & Designation & $\begin{array}{l}\text { Substrate } \\
\text { Type }\end{array}$ & $\begin{array}{l}\text { Coating } \\
\text { Thickness }\end{array}$ & Mode & Composition \\
\hline & $\begin{array}{l}\text { TCMT16T308 UF4215 } \\
\text { TCMT16T308 GC1115 } \\
\text { TCMT16T308 GC2030 }\end{array}$ & $\begin{array}{l}\text { WC-Co } \\
\text { WC-Co } \\
\text { WC-Co }\end{array}$ & $\begin{array}{l}14.5-17.5 \mu \mathrm{m} \\
2 \mu \mathrm{m} \\
2 \mu \mathrm{m}\end{array}$ & $\begin{array}{l}\text { CVD } \\
\text { PVD } \\
\text { PVD }\end{array}$ & $\begin{array}{l}\text { TiCN-Al }{ }_{2} \mathrm{O}_{3}-\mathrm{TiN} \\
\text { TiAlN-AlCrO } \\
\text { TiN-TiAlN }\end{array}$ \\
\hline
\end{tabular}


Table 3

Design of experiments considered for friction analysis.

\begin{tabular}{|c|c|c|c|c|c|}
\hline Nuances & Designation & $\begin{array}{l}\text { Substrate } \\
\text { Type }\end{array}$ & $\begin{array}{l}\text { Coating } \\
\text { Thickness }\end{array}$ & Mode & Composition \\
\hline & $\begin{array}{l}\text { TCMT16T308 UF4215 } \\
\text { TCMT16T308 GC1115 }\end{array}$ & $\begin{array}{l}\text { WC-Co } \\
\text { WC-Co }\end{array}$ & $\begin{array}{l}14.5-17.5 \mu \mathrm{m} \\
2 \mu \mathrm{m}\end{array}$ & $\begin{array}{l}\text { CVD } \\
\text { PVD }\end{array}$ & $\begin{array}{l}\mathrm{TiCN}-\mathrm{Al}_{2} \mathrm{O}_{3}-\mathrm{TiN} \\
\text { TiAlN-AlCrO }\end{array}$ \\
\hline
\end{tabular}

Table 4

Experimental parameters considered for friction tests.

\begin{tabular}{lllll}
\hline Composite & $\boldsymbol{\theta}\left({ }^{\circ}\right)$ & $\boldsymbol{P}\left(\mathrm{N} \mathrm{mm}^{-1}\right)$ & $\boldsymbol{V}_{\boldsymbol{S}}\left(\mathrm{m} \mathrm{min}^{-1}\right)$ & $\boldsymbol{w}_{\boldsymbol{c}}(\mathrm{mm})$ \\
\hline GFRP, CFRP & $0-90$ & $100-600$ & 50 & 4 \\
\hline
\end{tabular}

wear development. From the micrographs of Fig. 3i-l, the TiN intermediate layer shows relatively narrow worn area while the top TiAlN layer undergoes early material removal owing to severe abrasion. Contrary to the two other inserts, the TiAlN layer succeeds at preventing wear to penetrate into the following coating to the detriment of wide superficial worn area, up to cutting length approximating $25 \mathrm{~m}$ (micrograph of Fig. 3i). This patently proves the ability of TiAlN to delocalize wear when operating in aggressive contact conditions as governed by sharp glass fibers. The intermediate layer i.e. TiN, however, demonstrates ability to localize material removal at the maximum until advanced cutting stage (Fig. 31). By inspecting the TiN worn area, it was noticed that material removal doesn't evolve perfectly linearly versus cutting period since the TiN worn area fraction $\left(A_{f}\right)$ increases faster within $25-50 \mathrm{~m}$ than out of this domain. Nevertheless, it is virtually certain that abrasion regime on the coating set fluctuates from severe regular to severe irregular upon the two extreme constituents i.e. the substrate and the top layer. However, hard regular abrasion regime should describe quite better the intermediate layer behavior.

\subsection{CFRP cutting induced wear}

As for CFRP cutting, abrasion still remains dominating the flank wear upon all the used coatings. The examination of CVD coating reveals more vulnerability of TiN layer against CFRP than against GFRP. The top layer is released so early so as to transfer rapidly wear to the intermediate layer made of $\mathrm{Al}_{2} \mathrm{O}_{3}$. The former undergoes hard abrasion resulting in regular and pronounced wear patterns that appear as soon as cutting starts (Fig. 4a). The examination of worn CVD inserts reveals that CFRP cutting induces flank wear values of approximately 1.5 to 1.8 times higher than GFRP cutting while $l_{c}$ ranges in $25-100 \mathrm{~m}$.

However, the abrasion mode acting particularly on alumina phase switches from discontinuous irregular (Fig. 3a-d) to continuous regular (Fig. $4 \mathrm{a}-\mathrm{d}$ ), when the cut structure changes from GFRP to CFRP, respectively. When operating with CVD coating against CFRP, the substrate stands out because of the failure of fully coating set, at approximately $60 \mathrm{~s}$ cutting period.

While TiAlN-AlCrO (PVD) and TiCN-Al2O3-TiN (CVD) inserts show comparable worn area, the PVD coating constituents' seem to remove faster. The substrate emerges at early cutting stage (Fig. 4e). The TiAlN intermediate layer emerges also early through the top layer. This was mainly attributed to local cratering owing to fibers
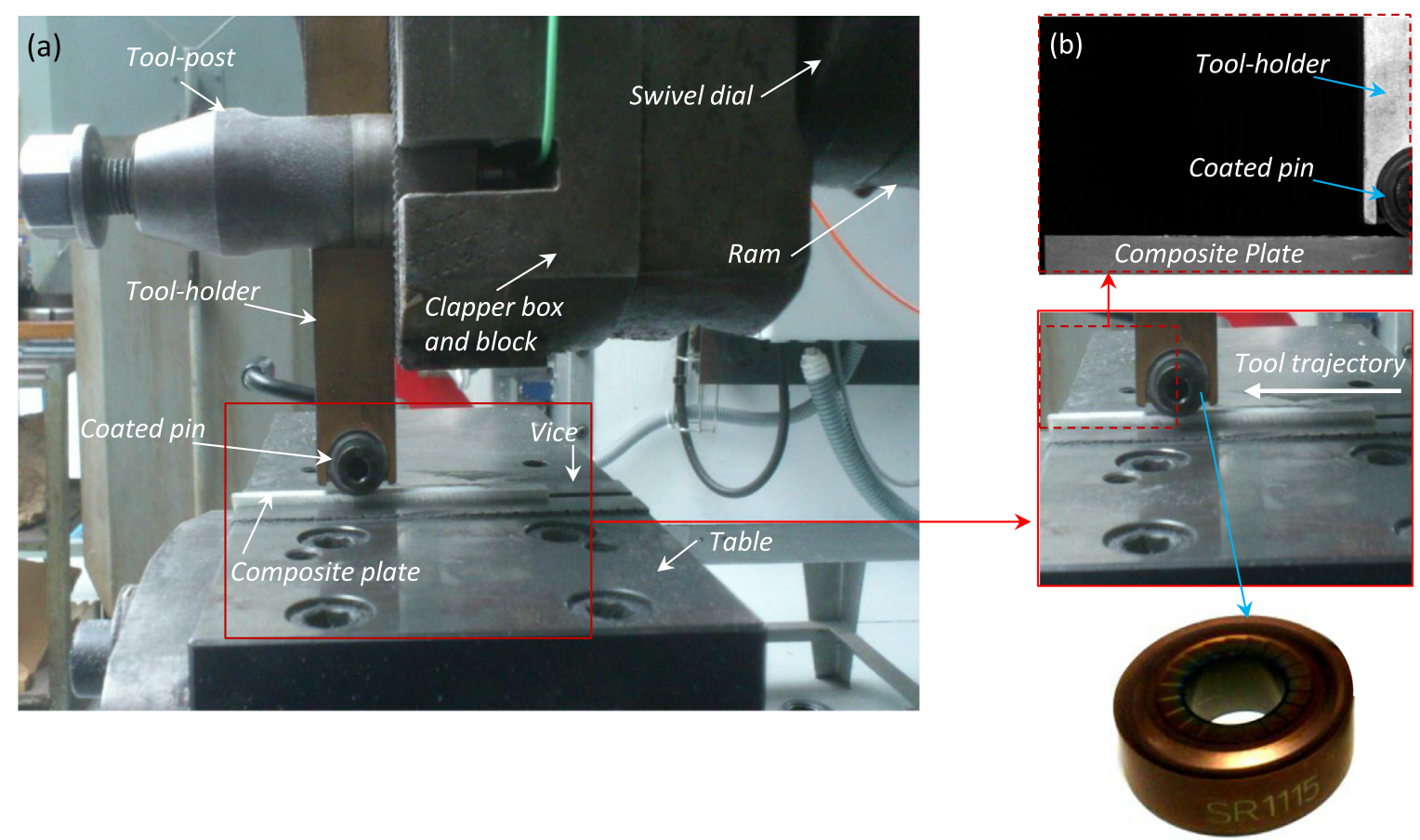

Fig. 2. Experimental set-up used for friction study. (a) Main machine parts, and (b) testing configuration. 

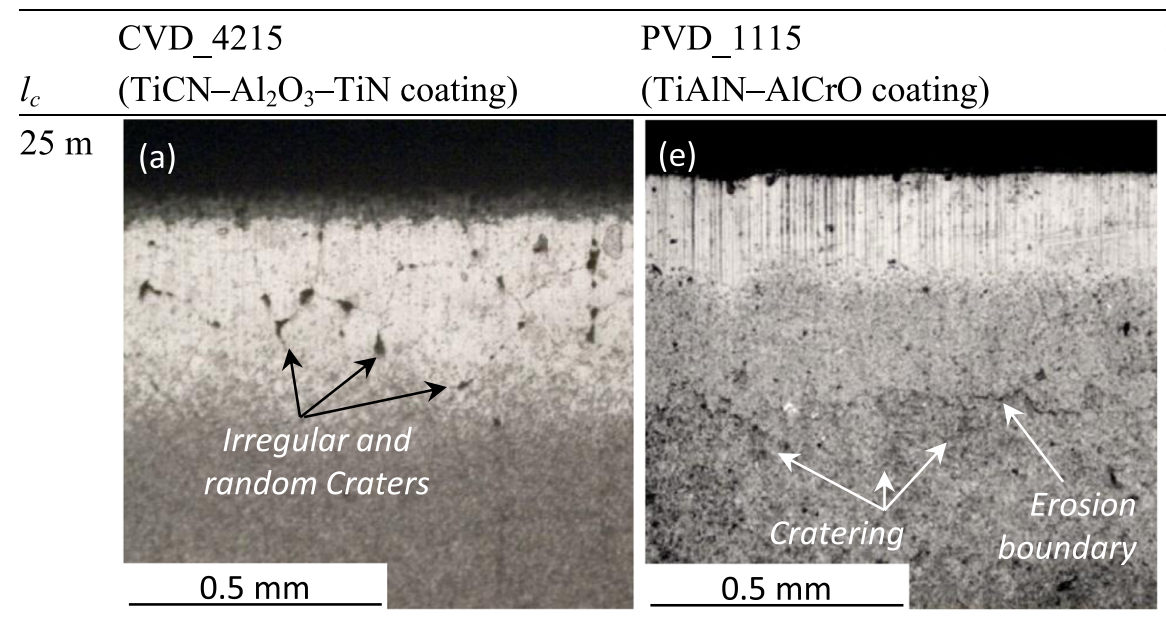

PVD_2030
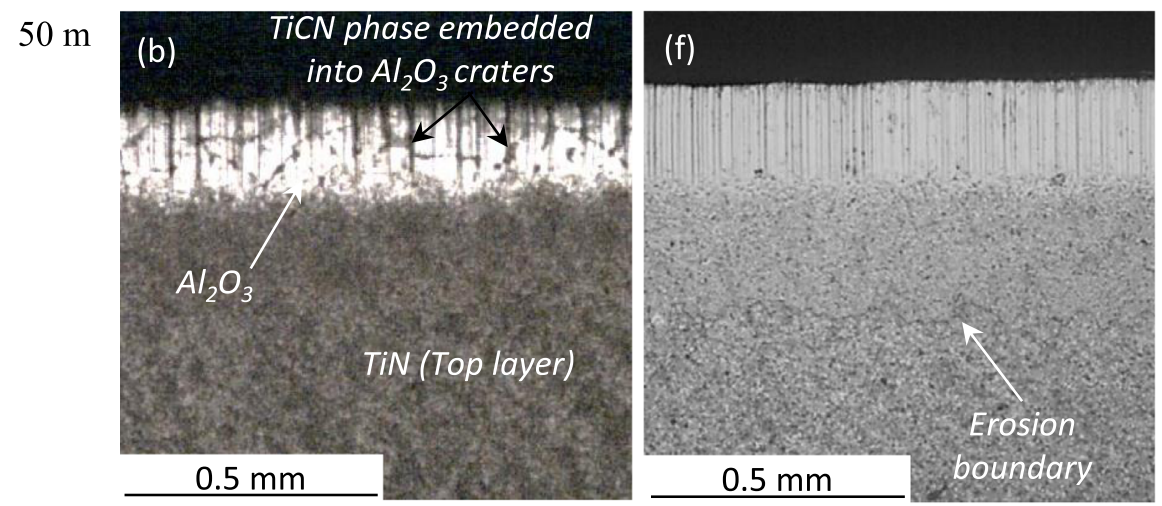

(TiN-TiAlN coating)
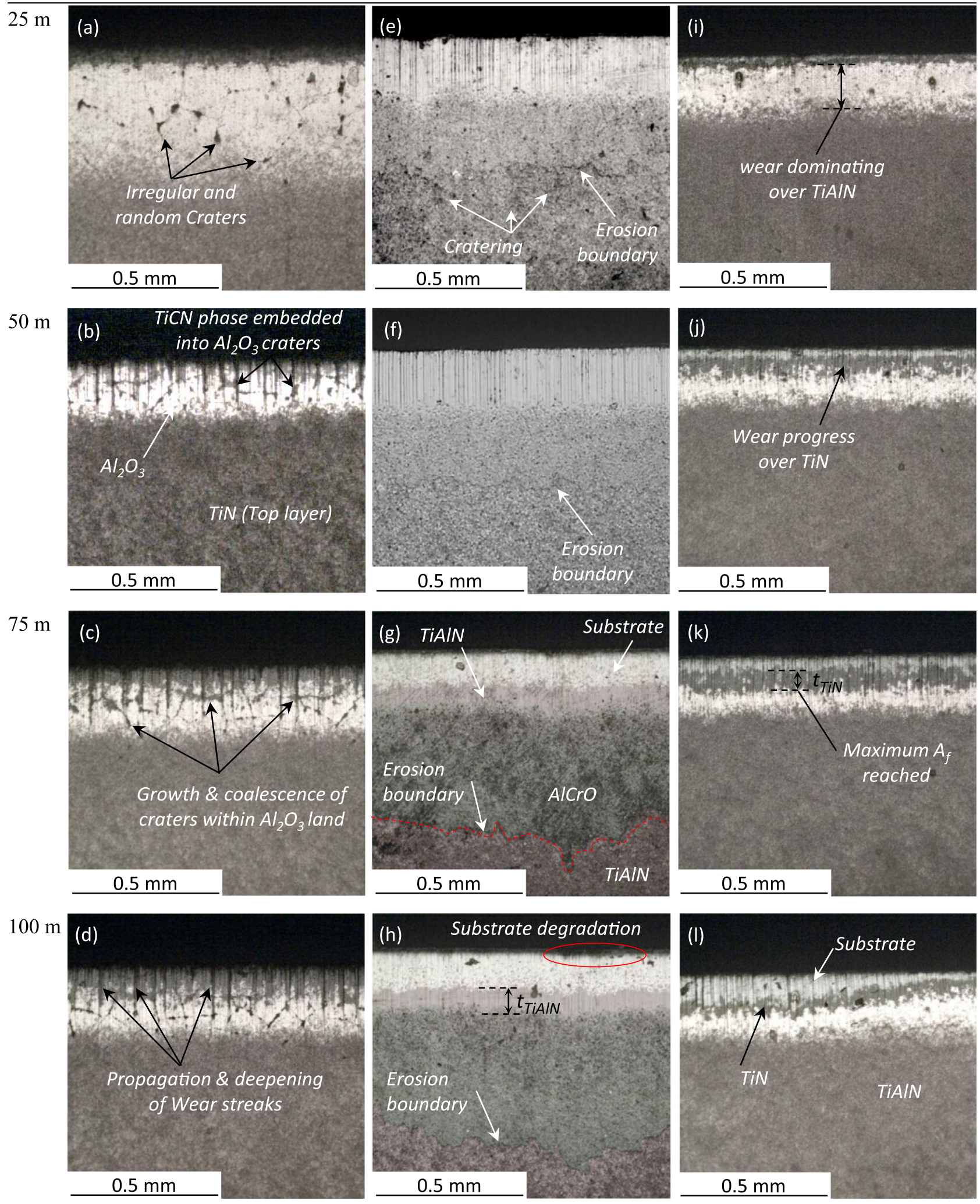

Fig. 3. Optical micrographs of worn inserts vs. cutting length obtained from GFRP cutting tests $\left(\theta=45^{\circ}\right)$.

spring-back that acts directly on the AlCrO top layer, and capable for uncovering the TiAlN sub-layer. Unlike to GFRP cutting tests, CFRP cutting tests lead to approximately same worn area upon the two
PVD coatings (Fig. 4i-l). However, it was found that wear mechanisms dominating the coating behavior upon TiN-TiAlN are, from one hand, (i) more severe, and, from the other hand, (ii) different to those 


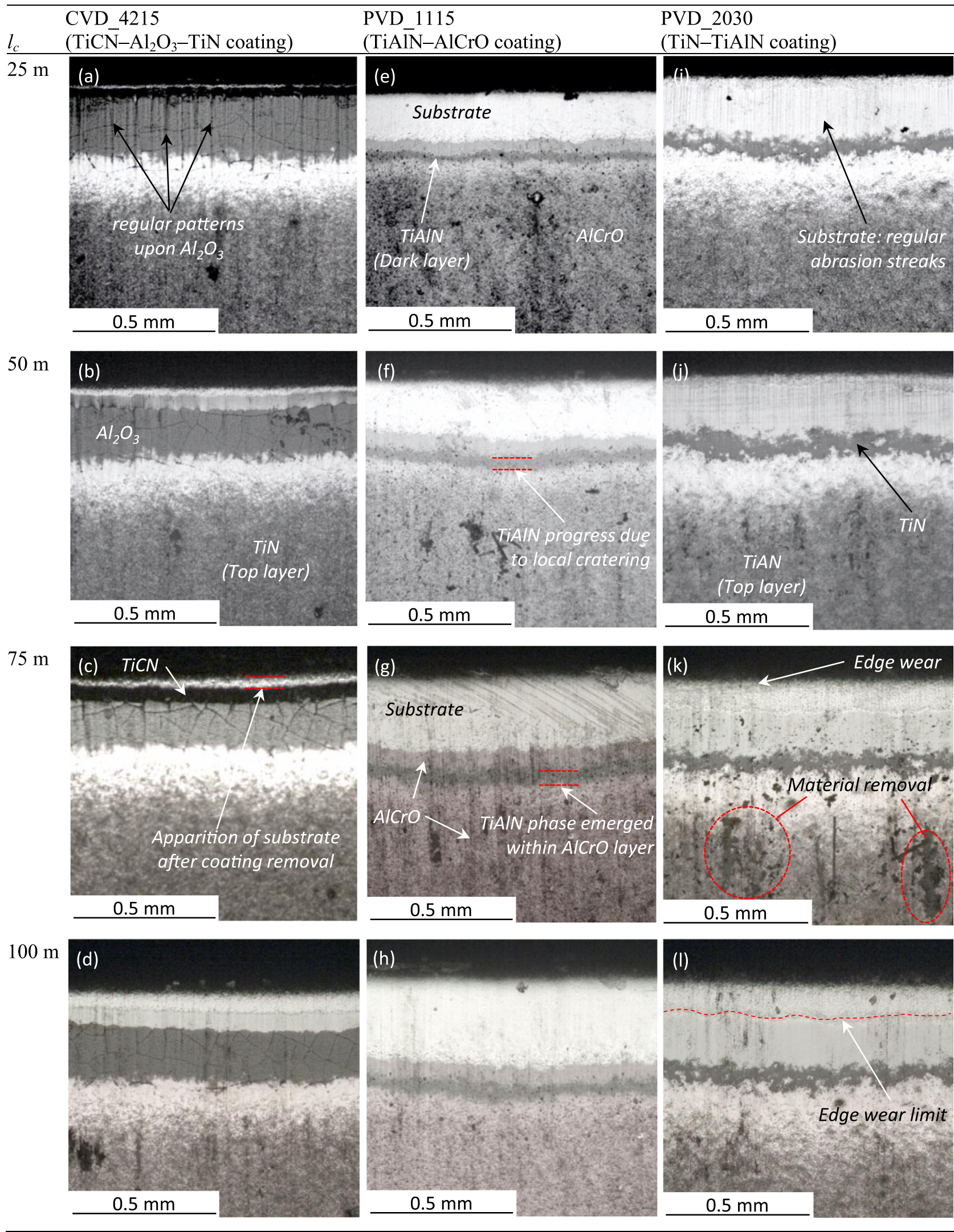

Fig. 4. Optical micrographs of worn inserts vs. cutting length obtained from CFRP cutting tests $\left(\theta=45^{\circ}\right)$.

observed on TiAlN-AlCrO. In fact, material pulls out through the TiAlN top layer, and the cutter edge rounds-off along the substrate (Fig. 4k-l). This results, in turn, in relatively neat different worn area fractions of TiAlN phase in the two PVD inserts.

\subsection{Effect of TiAlN "location" in wear progression}

The relative good property of TiAlN offers, actually, valuable solution for dry cutting applications. Cutting of heterogeneous 
Table 5

Wear modes dominating material removal process upon considered coatings. ${ }^{*}$ refers to wear modes over TiAlN.

\begin{tabular}{|c|c|c|c|c|c|}
\hline Material & Coating type & $\begin{array}{l}\text { Constituent } \\
\text { Substrate }\end{array}$ & 1st Intermediate layer & 2nd Intermediate layer & Top layer \\
\hline \multirow[t]{3}{*}{ GFRP } & $\mathrm{TiCN}-\mathrm{Al}_{2} \mathrm{O}_{3}-\mathrm{TiN}$ & & Mild abrasion & Hard abrasion/irregular cratering & Mild abrasion \\
\hline & TiAlN-AlCrO & Mild regular abrasion & Hard regular abrasion/ fine cratering* & - & Erosion dominant \\
\hline & TiN-TiAlN & Severe regular abrasion & Hard regular abrasion & - & Severe irregular abrasion* \\
\hline \multirow[t]{3}{*}{ CFRP } & $\mathrm{TiCN}-\mathrm{Al}_{2} \mathrm{O}_{3}-\mathrm{TiN}$ & Hard abrasion & Mild abrasion & Hard regular abrasion & Mild abrasion \\
\hline & TiAlN-AlCrO & Hard-to-severe abrasion & Mild-to-hard abrasion* & - & Mild abrasion/'local cratering' \\
\hline & TiN-TiAIN & Severe abrasion/edge wear & Severe abrasion & - & Severe abrasion/material removal* \\
\hline
\end{tabular}

materials such as unidirectional composite structures is among the primary beneficiaries. As a summary, Table 5 emphasizes the wear variation induced upon TiAlN layer due to cutting of both GFRP and CFRP composites, when it changes location from intermediate (TiAlN-AlCrO) to top (TiN-TiAlN).

- TiAlN vs. GFRP

When TiAlN layer changes location from intermediate to top, abrasion mechanisms dominating material removal process switches from hard to severe, respectively (Table 5). Wear patterns, besides, transform from regular to irregular, respectively. It is worth noting that hard abrasion at intermediate location combines with fine cratering. The former refers to a potential local material removal of the top coating layer because of resistance of TiAlN/AlCrO interface to progressive failure. As a top layer, TiAlN suffers from fiber spring-back resulting in variable streak depth. Although the TiAlN flank wear $\left(V_{B}\right)$ values developed at the two locations are very close $\left(r_{V_{B} G R P}^{G R P}=\frac{V_{B_{\text {int }}^{G}}^{G \text { GRP }}}{V_{B \text { top }}^{G C R P}} \approx 0.93\right)$, the worn area fraction $\left(A_{f}=t . r_{V B}\right)$ calculated at intermediate location is found, however, about 3 times lower $\left(r_{A_{f}}^{G F R P}=\frac{A_{f} \text { int }}{A_{f} \text { GFRP }} \approx 0.3\right)$ than that obtained at the top location (Fig. 5a), where $t$ is the composite plate thickness. At top location, hence, such a layer acts to delay, at maximum, wear to reaching the intermediate layer as practically observed in TiNTiAlN insert. As for intermediate location, it exhibited the shallowest and closest worn area which reflects its ability to moderate wear progression (i) firstly, by dissipating abrasion actions progressing from the top layer, and (ii) secondly, by delaying, accordingly, the substrate to enter into contact with the cut fibers.

- TiAlN vs. CFRP

The most significant transformation in wear behavior of TiAlN was detected during cutting of CFRP. Abrasion mechanisms was found able to pass from mild to severe regime when TiAlN changes location from intermediate to top. Additionally, typical material removal takes place upon that coating layer at top location (Table 5). The CFRP cutting tests yield TiAlN wear tendencies opposite to those obtained in GFRP cutting tests: The worn area fraction calculated for intermediate location increases from $\sim 9 \%$ to $\sim 17 \%$ while it decreases from $\sim 31 \%$ to $\sim 10 \%$ for top location while composite plate changes from GFRP to CFRP (Fig. 5b). Here, TiAlN flank wear measured at the intermediate location is approximately twice that measured at the top one, $\left(r_{V_{B}^{C F R P}}^{C R}=\frac{V_{B}^{\text {int }} \text { CRP }}{V_{B \text { top }}^{\text {CRP }}} \approx 2\right)$. Unlike to GFRP cutting case, the ratio between the worn area fractions resulting in CFRP cutting keeps roughly same value $\left(r_{A_{f}}^{C F R P}=\frac{A_{f}^{\text {Cint }}}{A_{f_{\text {top }}}^{\text {CFRP }}} \approx 1.8\right)$. It was found that flank wear and worn area fractions of TiAlN constituent obtained at GFRP cutting can be, respectively, related to those obtained at CFRP cutting. From experimental findings, the following relationships were especially deduced at $100 \mathrm{~m}$ cutting length:

$r_{V_{B}}^{G F R P}=\frac{1}{2} r_{V_{B}}^{C F R P}$

$r_{A_{f}}^{G F R P}=\frac{1}{2}\left[r_{A_{f}}^{C F R P}\right]^{-1}$

Irrespective to the insert used, the WC-Co substrate exhibits the most area fraction against CFRP because of relatively rapid removal of superior coating layers. Once these former fully disappear, the fibers enter in contact with the substrate allowing hence abrasion to develop within the active zone. In the case where the TiAlN layer occupies the intermediate location, the coating set shows better performance in protecting the substrate against GFRP than against CFRP. In fact, the coating set was found able for dissipating more than $80 \%$ of generated wear $\left(A_{f_{\text {coat }}}=A_{f_{\text {top }}}+A_{f_{\text {int }}}\right)$ when operating face to GFRP composite (a)

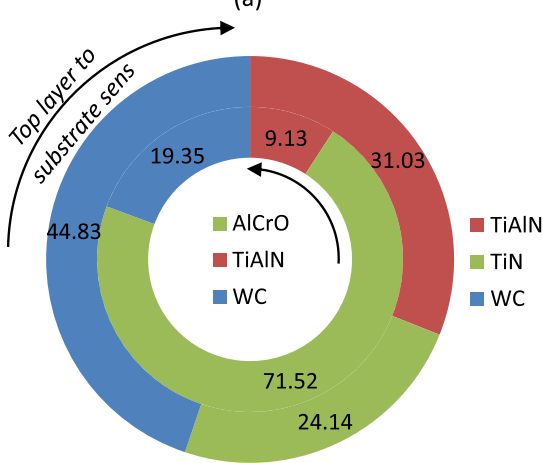

(b)

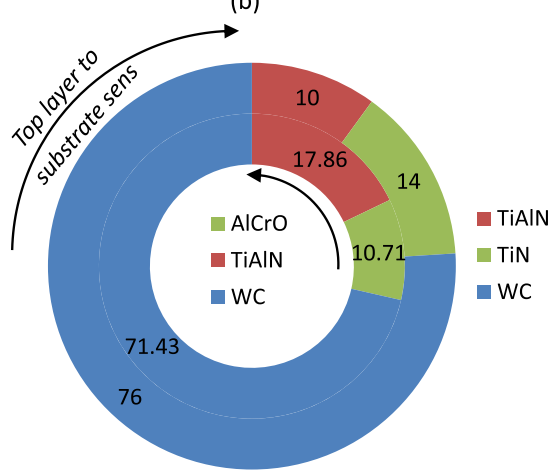

Fig. 5. Worn area fraction measured upon coating layers of each PVD insert at $l_{c}=100 \mathrm{~m}$. (a) GFRP cutting tests, and (b) CFRP cutting tests. 

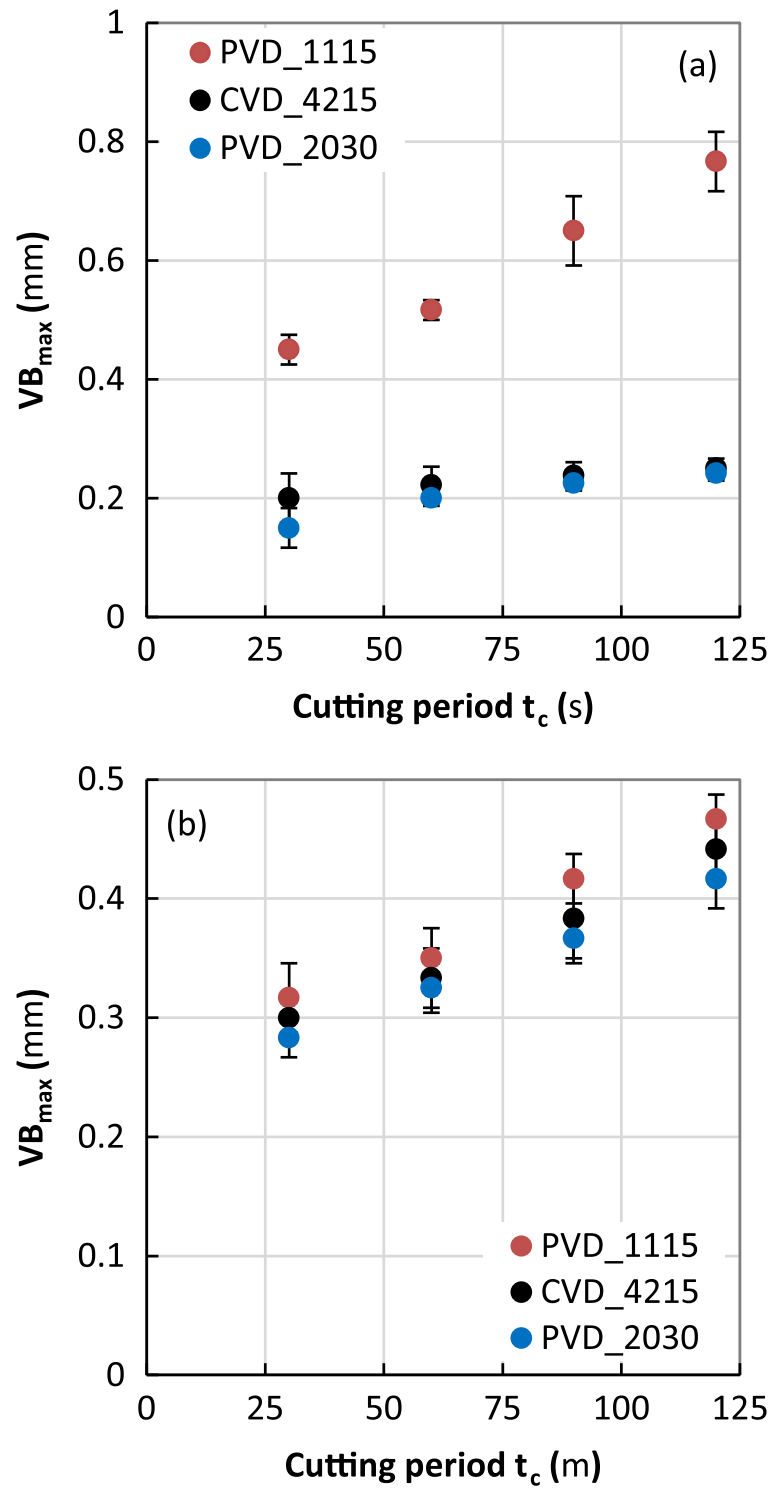

Fig. 6. Flank wear measured upon considered inserts $\left(\theta=45^{\circ}\right)$. (a) GFRP wear tests, and (b) CFRP wear tests.

compared to only $29 \%$ face to CFRP. The same conclusion might be outlined when TiAlN occupies the top layer since the whole coating area fractions $\left(A_{f-C o a t}\right)$ obtained in cutting GFRP and CFRP are, respectively, $55 \%$ and $24 \%$. This indicates the high vulnerability of PVD coating to resist the carbon fiber aggressiveness.

\subsection{Flank wear rate}

Fig. 6a and b show the maximum flank wear measured over the studied inserts. From tendencies, it is easily to distinguish the typical behavior of TiAlN-AlCrO versus GFRP if compared to the two other coatings.

The wear rate, $W=\frac{V_{B \max }}{t_{c}}$ where $t_{c}$ is the cutting lifetime, resulting from CFRP cutting tests was intentionally calculated for investigating the resistance to wear of the three inserts. The obtained values of $W$ show very close behavior between CVD and PVD insert. The wear rate is virtually constant for the three coated inserts since the values range in $0.0015-0.0017 \mathrm{~mm} \mathrm{~s}^{-1}$. The discrepancies were, however, found significantly larger when the inserts operates versus GFRP since $W$ exhibits wide variation range i.e. $0.0006-0.0036 \mathrm{~mm} \mathrm{~s}^{-1}$. Referring to the former values,
TiAlN-AlCrO coating records a wear rate versus GFRP of about two times higher than the rate obtained versus CFRP. This reflects, in turn, the vulnerability of such a coating set because of a premature failure of the top layer by effect of erosion. The CVD and TiN-TiAIN PVD coatings proved better efficiency to resist the wear progression within the cutting period.

\subsection{Apparent friction maps}

A tribological test reflecting the real technical configuration was proposed for investigating the reliability of multilayer coatings in cutting unidirectional fiber-reinforced composite structures. The TiAIN-AlCrO PVD coating behavior was especially compared to the CVD coating behavior. Fig. 7 shows the apparent friction maps versus both applied pressure and fiber orientation, built for the aforementioned inserts.

The measurements performed for GFRP plates using the two coating types lead to comparable plots (Fig. 7a and e). The apparent friction coefficient was found more sensitive to fiber orientation than pressure since $\mu_{a p}$ exhibits a non-linear behavior versus $\theta$ marking thus an inflection transition about $45^{\circ}$ along all pressure range. The friction values are as high as $\theta$ and $P$ are high. However, the variation gap appears more significant versus fiber orientation. The highest friction values were recorded within 60$90^{\circ}$. In such an orientation range, the number of cut fibers in contact with the tool is relatively high which explains, in part, the rise observed in apparent friction. However, $0^{\circ}$-fiber orientation shows the lowest values because the fiber circumferential surface favors sliding while fiber cut sections enhances adherence.

While CVD-on-CFRP tests (Fig. 7b) yield a tendency roughly similar to those obtained on GFRP, the PVD-on-CFRP tests (Fig. 7f doesn't lead to a so neat similitude with the map shown in Fig. 7b. It is worth noting that friction resulting in PVD coating fluctuates in larger ranges irrespective to fiber type (Table 6).

The friction range owing to PVD-on-GFRP tests records an enlargement of about $9.5 \%$ while PVD-on-CFRP tests lead to a three times higher percentage, namely $27.3 \%$ (Fig. $7 \mathrm{~g}$ and $\mathrm{h}$ ). The sensitivity of friction interval to the coating type can be respectively expressed for the two studied composite as,

$\mu_{\text {ap }}^{P V F R P}=\mu_{\text {ap }}^{C V D R P} \quad{ }^{+0.044}$

$\mu_{\text {ap } C F R P}^{P V D}=\mu_{\text {ap } C F R P}^{C V D} \quad{ }_{-0.131}^{+0.142}$

where $\mu_{a p_{i}}^{j}$ is the apparent friction for a specified deposition mode $i$ and specified composite material $j$.

Thus, the PVD coating looks more beneficial for cutting low fiber oriented structures regardless the fiber type and pressure. At relatively high fiber orientations, the CVD coating overcomes the PVD one (see Fig. 7c and d). This was essentially attributed to the further vulnerability of PVD coating against cut fibers acting in block for generating premature removal of coating layers. It should be mentioned, moreover, that PVD deposited layers are 7 to 9 times thinner than CVD deposited one which expose them to higher failure risk although their better adhesion to the substrate.

\subsection{Thermal conductivity}

AFM (DIMENSION Edge Veeco) was employed to analyze the thermal conductivity of both new and worn inserts by means of scratch test $[2,16]$. The test uses a thermal probe type VITA-DMGLA- 1 of $150 \mu \mathrm{m}$ in length as a resistive heater for scanning active zone of coated insert. During analysis, the temperature of the probe was kept constant by dint of an electric voltage adjustment 

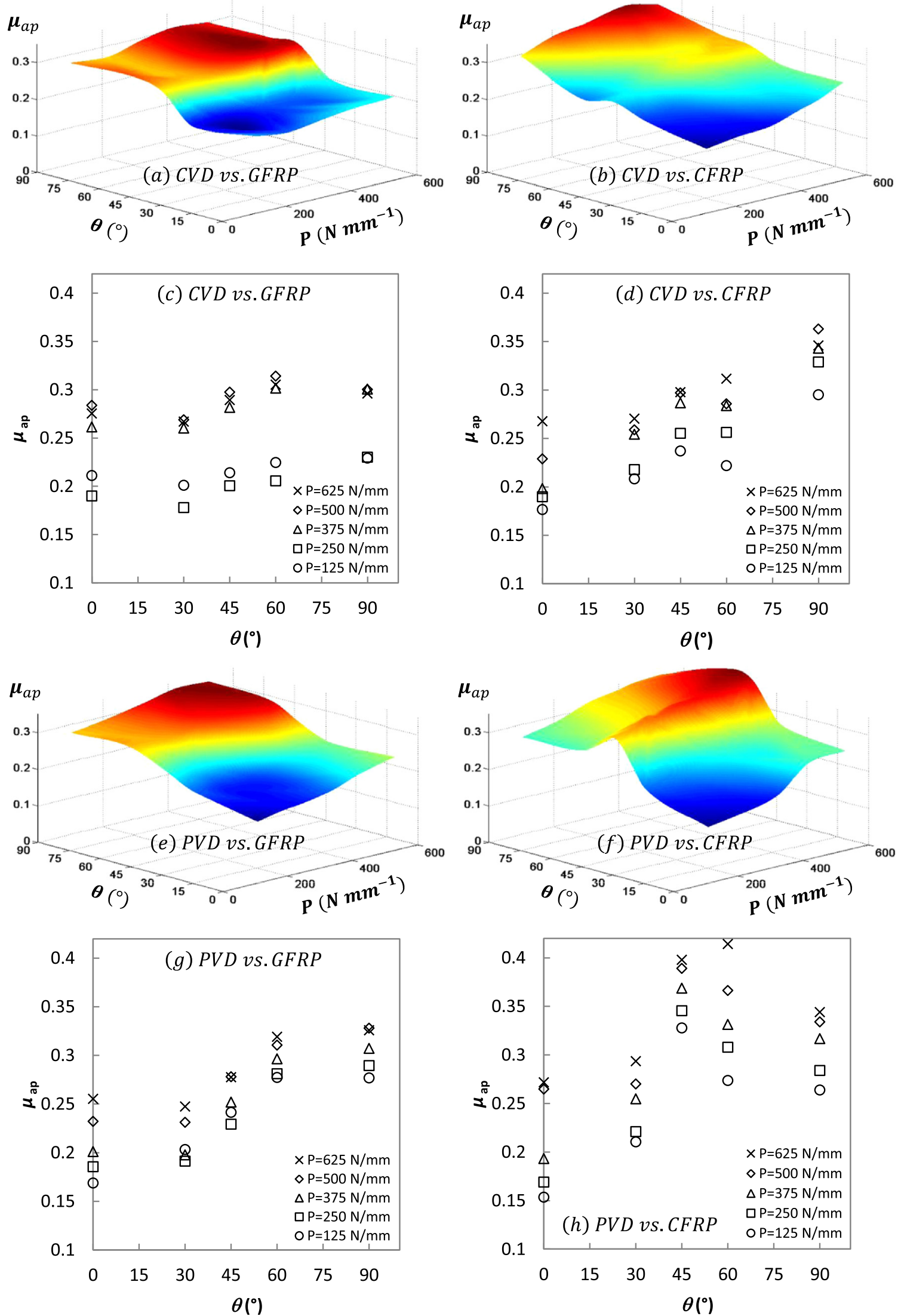

Fig. 7. Typical friction maps and friction evolutions obtained upon GFRP, and CFRP (SD: $0.086 \pm 0.03$ ). (a-d) CVD coating response, (e-f) PVD coating response. 
Table 6

Ranges of variation of friction coefficient, $\left(\mu_{a p-\min }-\mu_{a p-\max }\right)$.

\begin{tabular}{lll}
\hline & CVD_4215 & $\begin{array}{l}\text { PVD_1115 } \\
\text { (TiAlN-AlCrO) }\end{array}$ \\
\hline GFRP & $\left(\mathrm{TiCN}-\mathrm{Al}_{2} \mathrm{O}_{3}-\mathrm{TiN}\right)$ & $0.168-0.328$ \\
CFRP & $0.178-0.314$ & $0.153-0.414$ \\
\hline
\end{tabular}

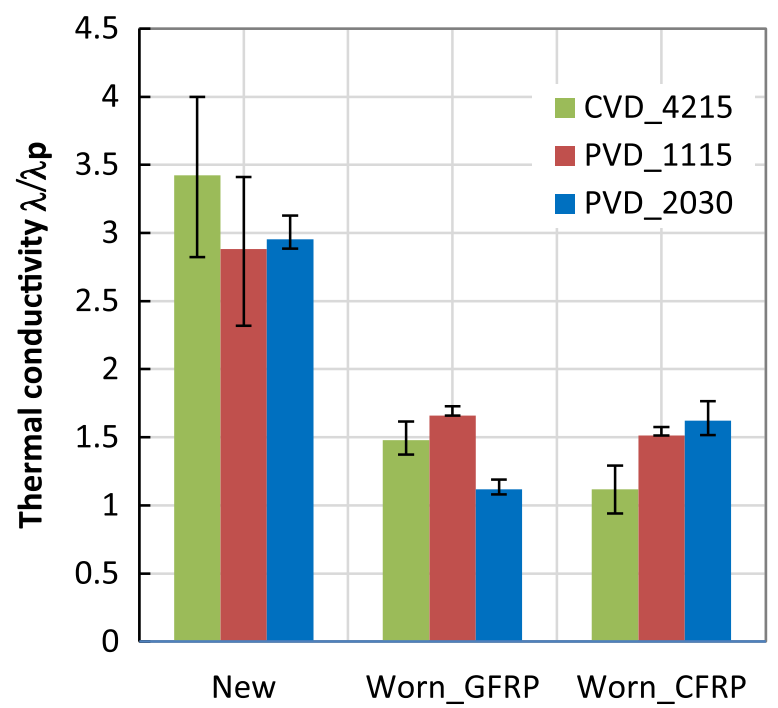

Fig. 8. Thermal conductivity values obtained on the considered inserts by AFM scratch tests at new and worn $\left(l_{c}=100 \mathrm{~m}\right)$ states.

[26-28]. As heat flow throughout the probe/insert interface is sensitive to thermal conductivity $(\lambda)$ variation, the scan area was kept constant for all the analyzed inserts. Any variation in $\lambda$ induces fluctuations in the output voltage. Contrast mode imaging analysis lead to deduce the thermal conductivity value as the average of the all data points to be measured throughout the scanned area. For comparison purposes, the measured $\lambda$-values were intentionally reported to the thermal conductivity measured upon glass/epoxy prepreg, using same methodology.

At new state, the three studied inserts commonly show higher relative thermal conductivity than that obtained at worn state (Fig. 8). In fact, there is no appreciable difference between thermal conductivities of the two PVD coatings at the new state. As obvious, the measured values at new state refer to the thermal conductivities of the top layer. The $\lambda$-values fall by approximately $50 \%$ after $120 \mathrm{~s}$ working period whatever the fiber type. This entails that wear process dominates the structure effect as for thermal conductivity variation.

As a proof, it was typically mentioned in open literature that $\lambda_{\text {TiN }}$ is relatively higher than $\lambda_{\text {TiAIN }}$ [29] which fits to the obtained results upon new inserts. A part of the lost coating, as particles or debris because of wear mechanisms, will be transferred to the composite cut area. This should play, somehow, to vary likely the thermal properties of the composite constituents [2]. In this case, the cut composite acts as thermal dissipater face to coating layer which explains, in some way, the drop in the thermal conductivity values observed upon all the studied inserts.

\section{Conclusions}

This paper addressed the reliability of typical TiAlN-based PVD coatings in cutting FRP composites. Wear and friction tests were performed in order to highlight, respectively, the material removal process and friction evolution versus testing conditions. The coating efficiency versus both glass/epoxy and carbon/epoxy was sensitively reported to the TiAlN layer location within the coating set. From experimental findings, the following conclusions can be drawn:

- While abrasion dominates wear upon CVD coating regardless the fiber type, it shows more vulnerability in cutting GFRP than in cutting CFRP. TiN top layer fails much earlier versus CFRP so as to transfer rapidly wear to $\mathrm{Al}_{2} \mathrm{O}_{3}$ intermediate layer.

- Unlike GFRP cutting tests, CFRP cutting tests yield so similar worn area upon both the TiN-TiAlN and TiAlN-AlCrO coatings while the former exhibits less severe wear mechanisms. As intermediate layer, TiAlN emerged early through the AlCrO top layer due to local cratering resulting in carbon fiber spring-back.

- The location of TiAlN within the PVD coating is of great role in controlling wear. Although it suffers from damage involved by the effect of fiber spring-back, such a layer acts in top location to delay at maximum the progression of in-depth wear face to GFRP. As intermediate layer, it plays to dissipate glass fiber induced abrasion progressing from the top layer, which delays, hence, the substrate failure. At that location, the entire coating set shows better efficiency in protecting the substrate against GFRP than against CFRP since it dissipates the most glass fiber induced wear as compared to carbon fiber induced one. This indicates the particular sensitivity of PVD coating to carbon fiber aggressiveness.

- The results of tribological tests revealed an extension of about 9.5\% in PVD-on-GFRP friction range and 27.3\% in PVD-on-CFRP, as compared to tests conducted, respectively, using CVD coating. PVD coating was found more beneficial at low fiber orientations irrespective to fiber type and pressure. However, PVD coatings exhibit vulnerability at higher orientations where cut fibers acts in package for enhancing premature coating damage.

\section{References}

1] Sundar M, Kamara AM, Mativenga PT, Li L. Synthesis of TiAIN based coating on mild steel substrate using combined laser/sol-gel technique. Surf Coat Technol 2010;204:2539-45.

[2] Ben Soussai A, Mkaddem A, El Mansori M. Effect of coating type on dry cutting of glass/epoxy composite. Surf Coat Technol 2013;215:413-20.

[3] Çalışkan H, Kurbanoğlu C, Panjan P, Čekada M, Kramar D. Wear behavior and cutting performance of nanostructured hard coatings on cemented carbide cutting tools in hard milling. Tribol Int 2013:62:215-22.

[4] Wu SK, Lin HC, Liu PL. An investigation of unbalanced-magnetron sputtered TiAlN films on SKH51 high-speed steel. Surf Coat Technol 2000;124:97-103.

[5] Tönshoff HK, Karpuschewski B, Mohlfeld A, Seegers H. Influence of subsurface properties on the adhesion strength of sputtered hard coatings. Surf Coat Technol 1999;116-119:524-9.

[6] Aihua L, Jianxin D, Haibing C, Yangyang C, Jun Z. Friction and wear properties of TiN, TiAIN, AlTiN and CrAIN PVD nitride coatings. Int J Refract Met Hard Mater 2012;31:82-8.

[7] Buhl R, Pulker HK, Moll E. TiN coatings in steel. Thin Solid Films 1981;80:26570.

[8] Kopaç J. Influence of cutting material and coating on tool quality and tool life. J Mater Process Technol 1998;78:95-103.

[9] Dobrzanski LA, Polok M, Adamiak M. Corrosion resistance of multilayer coatings deposited by PVD techniques onto the brass substrate. J Mater Process Technol 2005;164-165:816-21.

[10] Dobrzanski LA, Polok M, Adamiak MJ. Structure and properties of wear resistance PVD coatings deposited onto X37CrMoV5-1 type hot work steel. Mater Process Technol 2005;164-165:843-9.

[11] Bobzin K, Lugscheider E, Maes M, Gold PW, Loos J, Kuhn M. High-performance chromium aluminium nitride PVD coatings on roller bearings. Surf Coat Technol 2004;188-189:649-54.

[12] Bouzakis KD, Lontos A, Michailidisa N, Knotek O, Lugscheider E, Bobzin K, Etzkorn A. Determination of mechanical properties of electron beam-physical vapor deposition-thermal barrier coatings (EB-PVD-TBCs) by means of nanoindentation and impact testing. Surf Coat Technol 2003;163-164:75-80.

[13] PalDey S, Deevi SC. Single layer and multilayer wear resistant coatings of (Ti, Al)N: a review. Mater Sci Eng A 2003;342:58-79.

[14] PalDey S, Deevi SC. Properties of single layer and gradient (Ti, Al)N coatings. 
Mater Sci Eng A 2003;361:1-8.

[15] Li P, Chen L, Wang SQ, Yang B, Du Y, Li J, Wu MJ. Microstructure, mechanical and thermal properties of TiAlN/CrAlN multilayer coatings. Int J Refract Met Hard Mater 2013;40:51-7.

[16] Mkaddem A, Ben Soussia A, El Mansori M. Wear resistance of CVD and PVD multilayer coatings when dry cutting fiber reinforced polymers (FRP). Wear 2013;302:946-54.

[17] Hsieh JH, Liang C, Yu CH, Wu W. Deposition and characterization of TiAlN and multi-layered TiN/TiAlN coatings using unbalanced magnetron sputtering. Surf Coat Technol 1998;108-109:132-7.

[18] Barshilia HC, Prakash MS, Jain A, Rajam KS. Structure, hardness and thermal stability of TiAlN and nanolayered TiAIN/CrN multilayer films. Vacuum 2005;77:169-79.

[19] Ding XZ, Samani MK, Chen G. Thermal conductivity of PVD TiAlN films using pulsed photothermal reflectance technique. Appl Phys A 2010;101:573-7.

[20] Srinivasan R, Irudayaraj AA, Kuppusami P, Mohandas E, Kalainathan S, Ramachandran K. Photoacoustic studies on TiAIN nanostructured thin films. Int J Mod Phys B 2007;21:3889-900.

[21] An Q, Ming W, Cai X, Chen M. Effects of tool parameters on cutting force in orthogonal machining of T700/LT03A unidirectional carbon fiber reinforced polymer laminates. J Reinf Plast Compos 2015;34:591-602.

[22] Isbilir O, Ghassemieh E. Delamination and wear in drilling of carbon-fiber reinforced plastic composites using multilayer TiAIN/TiN PVD-coated tungsten carbide tools. J Reinf Plast Compos 2012;31:717-27.

[23] Gao CP, Guo GF, Zhao FY, Wang TM, Jim B, Wetzel B, Zhang G, Wang QH. Tribological behaviors of epoxy composites under water lubrication conditions. Tribol Int 2016;95:333-41.

[24] Xu X, Wang X, Liu W, Zhang X, Li Z, Du S. Microwave curing of carbon fiber bismaleimide composite laminates: material characterization and hot pressing pretreatment. Mater Des 2016;97:316-23.

[25] Esposito L, Sorrentino L, Penta F, Bellini C. Effect of curing overheating on interlaminar shear strength and its modelling in thick FRP laminates. Int J Adv Manuf Technol 2016:1-8.

[26] Luo K, Shi Z, Varesi J, Majumdar A. Sensor nanofabricataion, performance, and conduction mechanisms in scanning thermal microscopy. J Vac Sci Technol B 1997; 15:349-60.

[27] Luo K, Herrick RW, Majumdar A, Petroff P. Scanning thermal microscopy of a vertical-cavity surface-emitting laser. Appl Phys Lett 1997;71:1604-6.

[28] Mukherjee S, Watson P, Prance RJ. Non-contact measurement of local conductivity variations in carbon fibre based composite materials. J Phys Conf Ser 2011;307:1-5.

[29] Samani MK, Ding XZ, Khosravian N, Amin-Ahmadi B, Yi Y, Chen G, Neyts EC, Bogaerts A, Tay BK. Thermal conductivity of titanium nitride/titanium aluminum nitride multilayer coatings deposited by lateral rotating cathode arc. Thin Solid Films 2015;578:133-8. 